\title{
Anemia and Associated Factors Among Pregnant Women Attending Antenatal Care at Madda Walabu University Goba Referral Hospital, Bale Zone, Southeast Ethiopia
}

This article was published in the following Dove Press journal:

Journal of Blood Medicine

\author{
Sewnet Girma' \\ Tsion Teshome' \\ Meseret Worku' \\ Tinbit Solomon' \\ Selam Kehulu' \\ Reyana Aman' \\ Mitiku Bonsa ${ }^{2}$ \\ Tesfaye Assefa $\mathbb{D}^{\prime}$ \\ Habtamu Gezahegn (1D ${ }^{3}$ \\ 'Madda Walabu University Goba Referral \\ Hospital, School of Health Sciences, \\ Department of Nursing, Goba, Bale, \\ Ethiopia; ${ }^{2}$ Madda Walabu University \\ Goba Referral Hospital, School of Health \\ Sciences, Department of Public Health, \\ Goba, Bale, Ethiopia; ${ }^{3}$ Madda Walabu \\ University Goba Referral Hospital, \\ School of Medicine, Medical Physiology \\ Unit, Goba, Bale, Ethiopia
}

Background: Globally, anemia is a public health problem, particularly in developing countries, including Ethiopia. Pregnant women are at a higher risk for anemia and anemic pregnant women often develop complications. Early diagnosis of pregnant women for anemia saves both the life of the newborn and hers. Therefore, the present study intended to assess anemia and its associated factors among pregnant women attending at Madda Walabu University Goba referral hospital.

Methods: An institutional-based cross-sectional study was conducted from April 3 to May 3, 2019, among pregnant women attending Madda Walabu University Goba referral hospital. A total of 353 respondents were included in the study by using systematic random sampling techniques. Data were collected using both face-to-face interview and hemoglobin measurement. The collected data were entered into SPSS and analyzed using both bi-variable and multiple logistic regressions. Finally, statistical significance was declared at a $p$-value of less than 0.05 in the multiple logistic regressions.

Results: In this study, the prevalence of anemia was $46.2 \%$ (95\%CI: 40.9\%, 51.5\%). Factors significantly associated with anemia were positive stool examination for parasites (AOR=2.9, 95\%CI 1.255-6.856), lower consumption of fruits and vegetables ( $\mathrm{AOR}=2.7,95 \% \mathrm{CI} 1.47-$ 4.86), no iron supplementation ( $\mathrm{AOR}=2.2,95 \% \mathrm{CI} 1.07-4.45)$, large family size ( $\mathrm{AOR}=2.1$, 95\%CI 1.13-3.77), and absence of abortion history (AOR=0.4, 95\%CI 0.24-0.77).

Conclusions and Recommendation: Prevalence of anemia among pregnant women was high. Pregnant women with a previous history of abortion, positive stool for parasite, lower consumption of fruits and vegetables, no iron supplementation and large family size above five were risk factors for anemia. Therefore, encouraging pregnant women to take iron supplementation and to eat fruits and vegetables are important.

Keywords: anemia, pregnant women, hemoglobin, Ethiopia

\section{Background}

Anemia is a condition in which the number and size of red blood cells falls below an established cut-off value and during pregnancy anemia is defined as a hemoglobin concentration less than $11 \mathrm{~g} / \mathrm{dl} .{ }^{1}$ It can be caused by poor nutrition and poor health that affect women and can cause adverse outcomes to the well being of women and their neonatesoutcome. Some of those associated problems are less exercise tolerability, puerperal infection, thromboembolic problems,
Correspondence: Habtamu Gezahegn Madda Walabu University Goba Referral Hospital, School of Medicine, Medical Physiology Unit, P. O Box 302, Goba, Bale, Ethiopia

Tel +25I I 2306248

Email habgez47@gmail.com 
postpartum hemorrhage, pregnancy induced hypertension, placenta previa, cardiac failure, low birth weight, preterm delivery, and prenatal death. ${ }^{2}$ It affects not only women, people in all ages can be affected by anemia. ${ }^{3}$

Women and under-five children are mostly affected by anemia. Globally, about 1.62 billion people are affected by anemia and among these people about 56 million cases of anemia were found in pregnant women. ${ }^{4}$ Worldwide, deaths due to anemia were estimated to contribute to more than 115,000 maternal deaths and 591,000 prenatal deaths per year. ${ }^{5}$ Developing countries with poor socioeconomic development suffer much more from anemia compared to the developed countries. ${ }^{6}$

According to the World Health Organization (WHO) report the prevalence of anemia among pregnant women is $41.8 \%$, with the highest prevalence rate $(61.3 \%)$ found among pregnant women in Africa and 52.5\% among Southeast Asia. The report also revealed that, in subSaharan Africa the prevalence of anemia among pregnant women is estimated to be 17.2 million, which is approximately $30 \%$ of total global cases. ${ }^{7}$ In Ethiopia according to the Ethiopian Demographic and Health Survey (EDHS) report, $17 \%$ of reproductive age women are estimated to be anemic and $22 \%$ of the pregnant women are anemic. ${ }^{8}$

Globally, about $50 \%$ of anemia is caused by iron deficiency. ${ }^{9,10}$ Anemia can be caused with multiple causes that occur either by nutritional (vitamin and nutritional deficiencies) and non-nutritional (infectious). However, anemia caused by iron deficiency is one of the top ten global burden of diseases. ${ }^{11}$

Pregnant women are particularly vulnerable to develop anemia and an estimated $18 \%$ and $56 \%$ of pregnant women are anemic in industrialized and developing countries. ${ }^{12}$ Studies show that in sub-Saharan Africa and South Asia anemia was primarily the result of iron deficiency and severe anemia has been associated with an increased risk of stillbirth and infant mortality. ${ }^{13,14}$

In sub-Saharan Africa, the prevalence rate for pregnant women is $50 \%$ while that for non-pregnant women is $40 \%{ }^{15}$

Using anemia as an indicator and data collected from multiple countries, the WHO estimates that half of children and women and up to a quarter of men are irondeficient in developing countries. ${ }^{16}$

Anemia is a public health problem for pregnant women in Ethiopia according to WHO 2005 estimation of its Member States. ${ }^{17}$ In 2006 the micro nutrient initiative (MI) of Ethiopia estimated $27.0 \%$ and $30.6 \%$ prevalence of anemia among women of reproductive age and pregnant women respectively. ${ }^{18} \mathrm{~A}$ higher proportion of pregnant women are anemic (22\%) compared to women who are breastfeeding (19\%) and women who are neither pregnant nor breastfeeding $(15 \%) .{ }^{19}$ In the study area, there was no research conducted on this topic and the study was also unique as it included pregnant women from the pastoralist community. Knowing the prevalence and associated factors of anemia among pregnant women helps to work on the modifiable factors. Therefore, this study intended to assess the prevalence of anemia and associated factors among pregnant women attending at Madda Walabu University Goba referral hospital.

\section{Methods}

\section{Study Design, Area and Period}

An institutional-based cross-sectional study was conducted among pregnant women attending at Madda Walabu University Goba referral hospital. The study was conducted from April 3 to May 3, 2019. Madda Walabu University Goba referral hospital is located in Bale zone, Southeast Ethiopia. The hospital serves more than about 2 million people both from the zone and other nearby zones.

\section{Source Population, Sample Size and Sampling Technique}

The source population was all pregnant women attending at Madda Walabu University Goba referral hospital, $\mathrm{MCH}$ clinic for ANC follow-up. The sample size was computed using the general formula for a single population proportion. It was calculated by considering $36.6 \%$ prevalence of anemia among pregnant women, ${ }^{20} 5 \%$ margin of error and 95\% confidence interval (CI). Sample size was calculated by using single population proportion formulas as follows:

$$
\mathrm{n}=(\mathrm{Z} \alpha / 2)^{2 *}(\mathrm{P})^{*}(1-\mathrm{P})=(1.96)^{2} *(0.366) *(1-
$$
$0.366)=357$

$\mathrm{d}^{2}(0.05)^{2}$

Where, $\mathrm{n}=$ sample size

$\mathrm{P}=$ estimated prevalence of anemia in the study population is $36.6 \%$,

$\mathrm{d}^{2}=$ margin of error and

$Z \alpha \dot{\alpha} / 2=$ the value of standard normal distribution corresponding to a significant level of alpha.

By considering $5 \%$ non-response rate the total sample size was 375 for the study. 
Systematic sampling technique was used to select the study participants using the ANC registration book.

\section{Data Collection Tools and Procedure}

The data were collected using a pre-tested questionnaire initially prepared in English, then translated to both Afan Oromo and Amharic. The questionnaire included sociodemographic and health service utilization. Hemoglobin level and stool examination were extracted from the registration book and hemoglobin level less than $11 \mathrm{~g} / \mathrm{dl}$ considered as having anemia.

\section{Data Quality Issues}

Data collectors were fluent speakers of Afan Oromo and Amharic. Training was given for data collectors and supervisors for 2 days on the objective, relevance of the study and confidentiality of information. Data collection tools were pre-tested on $5 \%$ of the study subjects out of the selected hospital.

\section{Data Processing and Analysis}

The questionnaire was checked, cleaned, coded and entered to Epidata3.0.2 and analyzed by using SPSS version 20 . A bi-variable logistic regression model was primarily used to see the association of independent variables with anemia. Variables that had an association with anemia (at $p$-value of less than 0.25 ) in bi-variable logistic regression analysis were entered into the multivariable logistic regression analysis model to control the effects of confounders.

Finally, the variables that had a significant association were identified by calculating the odds ratio, while $95 \%$ confidence interval, and $p$-value less than 0.05 was used to declare statistical significance.

\section{Results}

\section{Socio-Demographic Characteristics of the Study Participants}

In this study, 353 study subjects participated with a response rate of $94 \%(353 / 375)$. Accordingly, the majority of the study participants $(244 ; 69.1 \%)$ were found to be in the age group of $18-25$, while $37(10.5 \%)$ study participants were in the group of 26-30 years (Table 1).

\section{Prevalence of Anemia Among Pregnant Women}

The study was conducted to assess prevalence and factors associated with anemia among pregnant women attending
Table I Socio-Demographic Characteristics of Study Participants on Anemia and Associated Factors Among Pregnant Women Attending at Madda Walabu University Goba Referral Hospital, Bale Zone, Southeast Ethiopia $(n=353)$

\begin{tabular}{|l|l|l|l|}
\hline \multicolumn{2}{|l|}{ Variables } & Frequency & Percentage \\
\hline Age (years) & $18-25$ & 244 & $69.1 \%$ \\
& $26-30$ & 37 & $10.5 \%$ \\
& Above 30 & 72 & $20.4 \%$ \\
\hline Family size & $1-5$ & 244 & $69.1 \%$ \\
& $6-9$ & 100 & $28.3 \%$ \\
& Above 10 & 9 & $2.5 \%$ \\
\hline Occupation & Housewife & 139 & $39.4 \%$ \\
& Employed & 106 & $30 \%$ \\
& Farmer & 99 & $28 \%$ \\
& Other & 9 & $2.5 \%$ \\
\hline Educational & No formal & 83 & $23.5 \%$ \\
status & education & & \\
& Formal education & 270 & $76.5 \%$ \\
\hline Monthly & Below 600 & 5 & $1.4 \%$ \\
income & Lo0-1500 & 122 & $34.6 \%$ \\
& Above 1500 & 226 & $64 \%$ \\
\hline Marital status & Married & 305 & $86.4 \%$ \\
& Unmarried & 18 & $5.1 \%$ \\
& Divorced & 30 & $8.5 \%$ \\
\hline
\end{tabular}

at Madda Walabu University Goba referral hospital $\mathrm{MCH}$ clinic for ANC follow-up. Accordingly, the prevalence of anemia among the pregnant women was $46.2 \%(95 \% \mathrm{CI}$ : $40.9 \%, 51.5 \%)$. However, the prevalence of anemia among pregnant women with a history of abortion was $62.9 \%$ and $38.5 \%$ among pregnant women with a family size of higher than five family members.

\section{Health Service Utilization of Pregnant Women}

In this study, pregnant women who attended for ante-natal care two times and above were $328(92.9 \%)$ and those who took iron supplementation were 285 (81\%). Stool examination was done for all of them and about $302(85.6 \%)$ of them were negative (Table 2).

\section{Bi-Variable and Multivariable Logistic Regressions Analysis}

Both bi-variable and multiple logistic regressions analysis were carried out. Accordingly, variables with $p$-value of less 
Table 2 Health Service Utilization of Study Participants on Anemia and Associated Factors Among Pregnant Women Attending at Madda Walabu University Goba Referral Hospital, Bale Zone, Southeast Ethiopia $(n=353)$

\begin{tabular}{|l|l|l|l|}
\hline Characteristics & & Frequency & Percentage \\
\hline Hemoglobin level & $\begin{array}{l}\text { Anemic } \\
\text { Non- } \\
\text { anemic }\end{array}$ & $\begin{array}{l}163 \\
190\end{array}$ & $\begin{array}{l}46.2 \\
53.3\end{array}$ \\
\hline Gravid & Multi & 277 & 75.5 \\
& Prim & 76 & 21.5 \\
\hline Types of pregnancy & Single & 307 & 80.0 \\
& Twin & 45 & 12.7 \\
& Triple & 1 & 3 \\
\hline History of abortion & Yes & 97 & 27.5 \\
& No & 256 & 72 \\
\hline Iron supplement & Yes & 285 & 81.0 \\
& No & 67 & 19.0 \\
\hline Stool examination & Negative & 302 & 85.6 \\
& Positive & 50 & 14.2 \\
\hline Antenatal care follow- & Yes & 328 & 92.9 \\
up & & & 7.1 \\
\hline
\end{tabular}

than 0.25 in the bi-variable logistic regressions analysis were used as candidates for multiple logistic regressions analysis. In this study, variables that were used in bi-variable logistic regressions analysis were history of abortion, stool examination, eating of fruits and vegetables, age of pregnant women, family size, and iron supplementation. However, in the multiple logistic regressions analysis, variables that were significantly associated with the dependent variable were: having no history of abortion ( $\mathrm{AOR}=0.4,95 \% \mathrm{CI} 0.24-0.77$ ), positive stool examination for parasites $(\mathrm{AOR}=2.9,95 \% \mathrm{CI}$ 1.26-6.86), lower consumption of fruits and vegetables ( $\mathrm{AOR}=2.7,95 \% \mathrm{CI} 1.47-4.86)$, no use of iron supplementation $(\mathrm{AOR}=2.2,95 \% \mathrm{CI} 95 \% 1.07-4.45)$, and large family size $(\mathrm{AOR}=2.1,95 \% \mathrm{CI} 1.13-3.77)$ (Table 3).

\section{Discussion}

Anemia is a public health problem among pregnant women. Globally, large numbers of pregnant women suffer from anemia and the problem is huge in developing countries including Ethiopia. Pregnant women with anemia experience different complications. Therefore, it is important to assess the prevalence and associated factors of anemia. The findings of this study are important because of the factors that were identified as being associated with anemia among pregnant women. In this study, the prevalence of anemia among pregnant women was 46.2\% $(40.9 \%, 51.5 \%)$. The finding of this study was higher compared to similar studies conducted in Shala Wereda, West Arsi (36.6\%), Southern Ethiopia (23.2\%), Gondar (21.6\%), Tikur Anbesa specialized hospital, Health centers in Addis Ababa (10.1\%), Sidama (31.6\%), Adama Town (28.1\%), Benchi Maji, Kefa and Sheka zones of public hospitals (19\%), Tanzania (18\%), Mizan Tepi University Teaching Hospital, South West Ethiopia (25.3\%), Adigrat General Hospital (7.9\%), Shire Town in Tigray (16.3\%), Felege Hiwot Hospital (20.8\%), Iran (16\%), and Nigeria. ${ }^{21-32}$ The possible reason might be due to

Table 3 Factors Associated with Anemia Among Pregnant Women Attending Madda Walabu University Goba Referral Hospital, Bale Zone, Southeast Ethiopia $(n=353)$

\begin{tabular}{|c|c|c|c|c|c|}
\hline \multicolumn{2}{|l|}{ Characteristics } & \multirow{3}{*}{$\begin{array}{l}\text { Non-Anemic No. (\%) } \\
36(37.1 \%) \\
154(60.2 \%)\end{array}$} & \multirow{3}{*}{$\begin{array}{l}\text { Anemic No. (\%) } \\
61(62.9 \%) \\
102(39.8 \%)\end{array}$} & \multirow{3}{*}{$\begin{array}{l}\text { COR }(95 \% \mathrm{Cl}) \\
\mathrm{I} \\
0.39(0.24-0.63)^{* *}\end{array}$} & \multirow{3}{*}{$\begin{array}{l}\text { AOR }(95 \% \mathrm{Cl}) \\
\mathrm{I} \\
0.4(0.236-0.77 \mathrm{I})^{*}\end{array}$} \\
\hline History of abortion & Yes & & & & \\
\hline & No & & & & \\
\hline \multirow[t]{2}{*}{ Eats fruit and vegetables } & $\geq$ twice per week & I0I (67.8\%) & $48(32.2 \%)$ & I & I \\
\hline & $\leq$ once per week & 89 (43.6\%) & II (56.4\%) & $2.72(1.75-4.23)^{* *}$ & $2.7(1.468-4.856)^{*}$ \\
\hline \multirow[t]{2}{*}{ Stool examination } & Negative & 177 (58.4\%) & $126(4 \mid .6 \%)$ & 1 & 1 \\
\hline & Positive & $13(26 \%)$ & 37 (74\%) & $4(2.042-7.83)^{* *}$ & $2.9(1.255-6.856)^{*}$ \\
\hline \multirow[t]{2}{*}{ Iron supplement } & Yes & 163 (57\%) & 123 (43\%) & 1 & I \\
\hline & No & $27(40.3 \%)$ & 40 (59.7\%) & $1.96(1.142-3.377)^{*}$ & $2.2(1.069-4.448)^{*}$ \\
\hline \multirow[t]{2}{*}{ Family size } & $<$ and $=5$ & 150 (6I.5\%) & 94 (38.5\%) & I & I \\
\hline & Above 5 & $40(38.1 \%)$ & 65 (6I.9\%) & $2.6(1.62-4.15)^{* *}$ & $2.1(1.132-3.7780)^{*}$ \\
\hline
\end{tabular}

Notes: *Significant at $p$-value $<0.05$, **significant at $p$-value $<0.00$ I. 
nutritional status difference. In our study area several pregnant women came from the pastoralist community in which malnutrition was common. The other possible reason might be that, in the pastoralist community, drinking tea was a common practice during eating foods. This practice can result in them becoming anemic since drinking tea at the same time as eating a meal will inhibit the absorption of iron. However, the prevalence of the present study was lower compared to studies conducted in urban areas of Eastern Ethiopia (56.8\%), Nekemte (52\%), Gilgel Gibe dam area (53.9\%), districts of India (84.9\%), India (68.6\%), Unguja Island in Tanzania (80.8\%) and Bangladesh (58.9\%). ${ }^{21,33-36}$ The possible reason might be due to the difference of study area. Another possible reason also might be due to some diseases which can cause anemia.

In this study, factors associated with anemia among pregnant women were positive stool examination, history of abortion, family size, lower consumption of fruit and vegetables and no iron supplementation. Accordingly, the odds of women who were positive for stool examination were about three times more likely to be anemic compared to those whose stools were negative $(\mathrm{AOR}=2.9,95 \% \mathrm{CI}$ 1.255-6.856). This might be due to parasites feeding on blood, resulting in the development of anemia. This finding was consistent with a study conducted in the Eastern zone of Tigray, Southern Ethiopia and Gondar town. ${ }^{22,28,37}$

Pregnant women who did not receive iron supplementation during their pregnancy were also significantly associated with anemia. Accordingly, the odds of being anemic were about two times among pregnant women who did not receive iron during their pregnancy compared to those who did $(\mathrm{AOR}=2.2,95 \% \mathrm{CI} 1.07-4.45)$. This finding was comparable with similar studies conducted in St. Paul's hospital in Addis Ababa, Gondar town, Sidama, Eastern and Southern Ethiopia. ${ }^{22,24,28,38,39}$ History of abortion was also significantly associated with anemia among the pregnant women. Bleeding during abortion can result in anemia. Most of the time in Ethiopia abortion is practiced traditionally and it also presents a risk to the life of women. In this study, the odds of being anemic among pregnant women with no history of abortion were about 0.4 less likely compared to the pregnant women who had a history of abortion ( $\mathrm{AOR}=0.4$, CI95\% 0.24-0.77) and this study was consistent with a study conducted in Mizan Tepi University Teaching Hospital, Southwest Ethiopia and Adigrat General hospital. ${ }^{23,32}$ Another factor associated with anemia among pregnant women was family size. In the study area most pregnant women attended from pastoralist community and they had large family sizes since most of them did not use family planning services. This large family size can mean food insecurity for many families. Accordingly, the odds of developing anemia among pregnant women with a large family size were about two times more likely to be anemic compared to pregnant women who had a smaller family size $(\mathrm{AOR}=2.1$, 95\%CI 1.132-3.77). This study was also consistent with a study conducted in Bangladesh. ${ }^{21}$ Eating fruits and vegetables less than one day per week was also significantly associated with anemia among pregnant women. The odds of being anemic among pregnant women who eat fruits and vegetables on less than 1 day per week were about three times compared to their counterparts.

\section{Conclusion}

In this study, the prevalence of anemia among pregnant women was high. Factors which were significantly associated with anemia were having a large family size, being positive for stool examination for parasites, not taking iron supplementation and rarely eating fruits and vegetables. Accordingly, encouraging pregnant women to take iron supplementation and eating fruits and vegetables are important.

\section{Strength and Limitation of the Study}

The strengths of this study were use of a large sample size and inclusion of an understudied population in the study. However, its limitations were the cross-sectional nature of the study and dietary diversity and anthropometric measurement such as MUAC were not assessed.

\section{Abbreviations}

ANC, antenatal care; AOR, adjusted odds ratio; CI, confidence interval; $\mathrm{COR}$, crude odds ratio; $\mathrm{MCH}$, maternal and child health; WHO, World Health Organization.

\section{Data Sharing Statement}

The data sets of the current study are available from the corresponding author on reasonable request.

\section{Ethical Approval and Consent to Participate}

This study was conducted in accordance with the Declaration of Helsinki. Ethical clearance was obtained from Madda Walabu University ethical committee. 
Written consent was obtained from the study participants after explaining the purpose of the study and the benefits.

\section{Acknowledgment}

We would like to thank the study participants, data collectors, supervisors, and Madda Walabu University Goba Referral Hospital MCH clinic staff.

\section{Author Contributions}

All authors had roles in the work reported, whether that was in the conception, study design, execution, acquisition of data, analysis and interpretation, or in all these areas; took part in drafting, revising or critically reviewing the article; gave final approval of the version to be published; have agreed on the journal to which the article has been submitted; and agree to be accountable for all aspects of the work.

\section{Funding}

No funding was obtained for this study.

\section{Disclosure}

The authors report no conflicts of interest in this work.

\section{References}

1. WHO. Essential nutrition actions improving maternal, newborn, infant and young child health and nutrition. BMC. 2014.

2. L PE K, Egri M, Deprem C, et al. The prevalence of nutritional anemia in pregnancy in an East Anatolian Province, Turkey. $B M C$. 2010;1:1-12.

3. Akhtar MHI. Severe anaemia during late pregnancy. Case Rep Obstet Gynecol BMC. 2012;1-3.

4. Y RU B, Ozaltin E, Shankar AH. Subramanian SV Anaemia in low-income and middle income countries. Public Health. 2011:1:125.

5. S TV S, Singh R. Gaikwad HS Evaluation of haematological parameters in partial exchange and packed cell transfusion in treatment of severe anaemia in pregnancy. Anemia BMC. 2012.

6. E CM M, Egli I, Wojdyla D, de Benoist B. Worldwide prevalence of anaemia BMC. 2008.

7. WHO. Worldwide prevalence of anemia, WHO vitamin and mineral nutrition informationsystem. Public Health. 2008:1:14.

8. Gebremedhin SEF. Correlates of anemia among women of reproductive age in Ethiopia. Public Health. 2005;22-23.

9. Galloway R. Anemia prevention and control: what works. USAID, The World Bank, UNICEF, PAHO, FAO. Micronutrient Initiative. 2003.

10. SCN. The fourth report on the world nutrition situation: nutrition throughout the life cycle. Standing Committee Nutrition United Nations Sys. 2000.

11. WHO. The World Health Report. Reducing Risks, Promoting Healthy Life. Geneva: World Health Organization; 2002.

12. WHO. Iron Deficiency Anemia: Assessment, Prevention and Control: A Guide for Programme Managers. Geneva, Switzerland: UNICEF, United Nations University, WHO; 2001.
13. Lone F, Qureshi R, Emanuel F. Maternal anaemia and its impact on perinatal outcome. Trop Med Int Health. 2004;9(4):486-490. doi:10.1111/j.1365-3156.2004.01222.x

14. Brabin B, Premji Z, Pelletier D. An analysis of anemia and child mortality. J Nutr. 2001;131:2S.

15. FMOH. National Guideline for Control and Prevention of Micronutrient Deficiencies; 2004.

16. UNICEF/UNU/WHO/MI. Preventing Iron Deficiency in Women and Children: Background and Consensus on Key Technical Issues and Resources for Advocacy, Planning, and Implementing National Programs. Geneva: UNICEF/UNU/WHO/MI Technical Workshop; 1998:1998.

17. WHO. Worldwide Prevalence of Anaemia 1993-2005: WHO Global Database on Anaemia/Edited by Bruno De Benoist, Erin Mclean, Ines Egli and Mary Cogswell; 2008.

18. MI(micronutrient/initaitaive). Micro nutrient initiative Ethiopia country profit the institute http://WWWmicronutrientorg. 2006.

19. Central Statistical Agency(CSA) EM. Demographic and Health Survey 2011. Addis Ababa, Ethiopia and Calverton, MD, USA: CSA and ORC Macro; 2011.

20. Obse N, Mossie A, Gobena T:. Magnitude of anemia and associated risk factors among pregnant women attending antenatal care in Shalla Woreda, West Arsi zone, Oromia region, Ethiopia. Ethiop Health Sci. 2013;23(2):165-173.

21. Ahmed S, Al Mamun MAA, Mahmud N, et al. Prevalence and associated factors of anemia among pregnant women receiving antenatal care (ANC) at Fatima Hospital in Jashore, Bangladesh: a cross-sectional study. Food Nutr Sci. 2019;10(9):1056-1071. doi:10.4236/fns.2019.109076

22. Alem M, Enawgaw B, Gelaw A, Kena T, Seid M, Olkeba Y. Prevalence of anemia and associated risk factors among pregnant women attending antenatal care in Azezo Health Center Gondar Town. Northwest Ethiopia. J Int Histopath. 2013;1(3)1.

23. Brhane Berhe FM, Legese H, Gebrewahd A, et al. Prevalence of anemia and associated factors among pregnant women in Adigrat General Hospital, Tigrai, northern Ethiopia, 2018. BMC Res Notes. $2019 ; 12$.

24. Gebremedhin S, Enquselassie F, Umeta M. Prevalence and correlates of maternal anemia in rural Sidama, Southern Ethiopia. Afr J Reprod Health. 2014;18(1):44-53.

25. Gudeta TA, Regassa TM, Belay AS, Kabir R. Magnitude and factors associated with anemia among pregnant women attending antenatal care in Bench Maji, Keffa and Sheka zones of public hospitals, Southwest, Ethiopia, 2018: a cross-sectional study. PLoS One. 2019;14(11):e0225148. doi:10.1371/journal.pone.0225148

26. Kebede A, Gerensea H, Amare F, Tesfay Y, Teklay G. The magnitude of anemia and associated factors among pregnant women attending public institutions of Shire Town, Shire, Tigray, Northern Ethiopia, 2018. BMC Res Notes. 2018;11(1):1-6. doi:10.1186/s13104-0183706-x

27. Lashkardoost H, Doust HM, Saadati H, Nazari Z, Joshaghan MS, Hamedi A. Prevalence of hemoglobin anemia among pregnant women in the Northeast of Iran. J Community Health Res. 2019.

28. Lebso M, Anato A, Loha E, Clarke SL. Prevalence of anemia and associated factors among pregnant women in Southern Ethiopia: A community based cross-sectional study. PLoS One. 2017;12(12): e0188783. doi:10.1371/journal.pone.0188783

29. Mohammed E. Magnitude of anemia and associated factors among pregnant women visiting public health institutions for antenatal care services in Adama Town, Ethiopia. Central African J Public Health. 2018;4(5):149-158. doi:10.11648/j.cajph.20180405.14

30. Obse N, Mossie A, Gobena T. Magnitude of anemia and associated risk factors among pregnant women attending antenatal care in Shalla Woreda, West Arsi Zone, Oromia Region, Ethiopia. Ethiop J Health Sci. 2013;23(2):165-173. 
31. Stephen G, Mgongo M, Hussein Hashim T, Katanga J, StrayPedersen B, Msuya SE. Anaemia in pregnancy: prevalence, risk factors, and adverse perinatal outcomes in Northern Tanzania. Anemia. 2018;2018.

32. Zekarias B, Meleko A, Hayder A, Nigatu A, Yetagessu T. Prevalence of anemia and its associated factors among pregnant women attending antenatal care (ANC) in Mizan Tepi University Teaching Hospital, South West Ethiopia. Health Sci J. 2017;11(5):1-8. doi:10.21767/1791-809X.1000529

33. Getachew M, Yewhalaw D, Tafess K, Getachew Y, Zeynudin A. Anaemia and associated risk factors among pregnant women in Gilgel Gibe dam area, Southwest Ethiopia. Parasit Vectors. 2012;5 (1):296. doi:10.1186/1756-3305-5-296

34. Mihiretie H, Anane Mitiku M. Magnitude of anemia and associated factors among pregnant women attending antenatal care in Nekemte health center, Nekemte, Ethiopia. J Med Microbiol Diagnosis. 2015;4 (3):1. doi:10.4172/2161-0703.1000197

35. Toteja G, Singh P, Dhillon B, et al. Prevalence of anemia among pregnant women and adolescent girls in 16 districts of India. Food Nutr Bull. 2006;27(4):311-315. doi:10.1177/156482650602700405
36. Ali MM, Ngowi AF, Gibore NS. Prevalence and obstetric factors associated with anaemia among pregnant women, attending antenatal care in Unguja island. Int J Community Med Public Health. 2019;6 (3):950-995

37. Berhe K, Fseha B, Gebrehiwot Gebremariam HT, Etsay N, Welu G, Tsegay T. Risk factors of anemia among pregnant women attending antenatal care in health facilities of Eastern Zone of Tigray, Ethiopia, case-control study, 2017/18. Pan Afr Med J. 2019;34.

38. Gebreweld A, Tsegaye A. Prevalence and factors associated with anemia among pregnant women attending antenatal clinic at St. Paul's Hospital Millennium Medical College, Addis Ababa, Ethiopia. Adv Hematol. 2018.

39. Addis Alene K, Mohamed Dohe A. Prevalence of anemia and associated factors among pregnant women in an urban area of Eastern Ethiopia. Anemia. 2014;2014.
Journal of Blood Medicine

\section{Publish your work in this journal}

The Journal of Blood Medicine is an international, peer-reviewed, open access, online journal publishing laboratory, experimental and clinical aspects of all aspect pertaining to blood based medicine including but not limited to: Transfusion Medicine; Blood collection, Donor issues, Transmittable diseases, and Blood banking logistics; Immunohematology; Artificial and alternative blood based

\section{Dovepress}

therapeutics; Hematology; Biotechnology/nanotechnology of blood related medicine; Legal aspects of blood medicine; Historical perspectives. The manuscript management system is completely online and includes a very quick and fair peer-review system. Visit http://www.dovepress.com/testimonials.php to read real quotes from published authors. 